\title{
Performance-Based Design as a Strategy for Risk Reduction: Application to Seismic Risk Assessment of Composite Steel-Concrete Frames
}

\author{
Giuliano Augusti and Marcello Ciampoli \\ Department of Structural and Geotechnical Engineering, Sapienza Università di Roma \\ giuliano.augusti@uniroma1.it, marcello.ciampoli@uniroma1.it
}

\begin{abstract}
Performance-based design is an efficient strategy for assessing and reducing the risk that a construction violates some performance requirement. In this paper, a procedure for performance-based assessment of seismic risk is illustrated with reference to a composite steel-concrete frame structure. Such risk is conventionally evaluated in a simplified formulation, i.e. as the mean annual frequency of exceeding a threshold level of damage in any significant structural element. The procedure is applied to evaluate the site seismic hazard, the structural damage, the corresponding capacity, and finally the seismic risk of a plane frame, extrapolated from a 3-D structure that was subjected to experimental tests at the ELSA-JRC Laboratory in Ispra, Italy. Specific attention is given to the choice of the intensity and damage measures for use in performance-based seismic risk assessment of composite steel-concrete frames.
\end{abstract}

\section{Introduction}

By definition, "Performance-Based Design" (usually referred to by the acronym PBD) requires the satisfaction of the relevant performance requirements with a sufficiently high probability throughout the lifetime of an engineering system.

This definition might appear a truism, since design is always addressed to fulfill one or more performance objectives. Indeed, PBD is a new concept not because it refers to performance objectives, but in the way it aims at fulfilling these objectives.

As a matter of fact, up to a few years ago, the fulfillment of performance objectives was based on engineering experience and practice; PBD is instead a design philosophy specifically constructed in order to reach rationally and with a given reliability the chosen objectives [14 $15|2| 27|28| 26]$.

The basic document for all Structural Eurocodes, i.e. EN 1990: "Eurocode - Basis for Structural Design" (CEN, 2002), begins with the statement: "A structure shall be designed and executed in such a way that it will, during its intended life, with appropriate degrees of reliability and in an economical way: (i) sustain all actions and influences likely to occur during execution and use, and (ii) remain fit for the use for which it is required". Thus, in principle the Code recognizes correctly that the fulfillment of the chosen objectives cannot be guaranteed in deterministic terms, but rather tackled in a probabilistic context ("appropriate degrees of reliability"); recognizes also that such fulfillment is conditioned by cost/benefit problems ("in an economical way"). However,

A. Korytowski et al. (Eds.): System Modeling and Optimization, IFIP AICT 312, pp. 3-20, 2009.

(c) IFIP International Federation for Information Processing 2009 
the Structural Eurocodes prescribe practical design rules that have little "performancebased" character, and in actual fact make them prescriptive codes; the same happens with the 2005 Italian Building Code [24].

A general definition of PBD, derived from the specific definition given by SEAOC for Performance Based Seismic Design [29], is the following: "Performance Based Engineering consists of those actions, including site selection, development of conceptual, preliminary and final design, construction and maintenance of a structure over its life, to ensure that it is capable of predictable and reliable performances. The life of a structure includes also its decommissioning and/or demolition. Each of the above actions can have significant impact on the ability of the structure to reliably reach desired performances".

At present, PBD is still far away from providing a consistent set of design rules, and will probably remain for some time only a philosophy on the verge of utopia. However, this should not be regarded as a negative aspect: as a matter of fact, the very scope of engineering is to conceive, design and build facilities that are better, more effective and economical than present ones. This most probably will never be fully achieved and only partial steps will be possible, but such a high objective cannot be pursued at without an ideal vision: and PBD appears to be at the moment the best [21].

The difficulties encountered in applying the PBD philosophy are put in evidence by the everyday experience of the engineers and their limited capacity of governing the choices in the several stages of the facility lifetime: choice of the location, conceptual design, preliminary and final design, construction, maintenance, decommissioning and/or demolition. Already the choice of the site of a facility is often not the result of a rational strategy but of many casual chances. Conceptual design includes aesthetic, functional and structural aspects: these aspects are interrelated and should be tackled in a systematic way, aimed at fulfilling the performance objectives; however, much too often the engineer's role is limited to the choice of the load-carrying system. Preliminary and final design are the stages in which the influence of the engineer is highest: however, he often cannot control choices essential for the performance objectives, such as construction details, heating and electrical systems, etc. Similar considerations apply to other stages, from construction to demolition.

According to the International Code Council [17], the performance capacities of a structure can be verified in three ways: by design computations; by experimental tests; by the respect of appropriate code guidelines (the last being the actual way in which most regulations, and specifically the Eurocodes, are implemented).

Thus, rather than being an alternative to prescriptive codes, PBD is in reality an approach that does not exclude guidelines, but is aimed directly at the rational achievement of well specified performance objectives and/or their optimization: once the performance objectives are defined, the designer can limit himself to demonstrate that he has respected the code guidelines aimed at fulfilling those objectives [6].

PBD has been originally formulated in a systematic way for structures subject to seismic hazard: but applications to other hazards have also been implemented.

An example is Performance-Based Blast Engineering that had a significant development in the US after the terrorist attacks to World Trade Center in 1993 and 2001, to Murrah Building in 1995 and to Pentagon in 2001 [33]. To take into account in the 
design the possible effects of explosions is now considered an added value by building owners and insurance companies.

A field of great potential for developments of PBD procedure is Wind Engineering: the first steps in this direction go back to an Italian research project (PERBACCO: 2003/2005), in which the expression "Performance-based Wind Engineering" (PBWE) was coined [4]. A recent example can be found in [30].

Also this paper will be limited to seismic design. In what follows, after a brief presentation of the general framework, the application of PBD to the evaluation of the seismic risk (although conventionally defined) of a composite steel-concrete frame will be illustrated in detail.

\section{Formulation of the Problem}

Concerning the demonstration of the capacity of a structure to fulfill the stated performance objectives under seismic hazard, one can refer to the equation proposed by the Pacific Earthquake Research Center (PEER) for PB seismic design [11].

In quantitative terms, the performance requirement is identified with an acceptable value of the mean annual frequency $\lambda(\mathrm{LS})$ of exceeding a limit state LS of the structure, assessed combining the site seismic hazard and the structural vulnerability by the Total Probability Theorem, through the relation:

$$
\lambda(\mathrm{LS})=\iint \mathrm{G}(\mathrm{LS} \mid \mathrm{DM}) \cdot d \mathrm{G}(\mathrm{DM} \mid \mathrm{IM}) \cdot d \lambda(\mathrm{IM})
$$

where:

1. IM is an appropriate "intensity measure" of the earthquake;

2. $\lambda(\mathrm{IM})$ is the mean annual occurrence rate in the considered site of a quake of intensity equal or larger than IM (i.e. the measure of the seismic hazard in the relevant site);

3. DM is a parameter obtained from the analysis of the structural response and measuring the structural damage;

4. G(DMIIM) is the conditional probability of overcoming DM for a given IM;

5. LS is the considered "limit state";

6. G(LSIDM) is the conditional probability of overcoming LS for a given DM.

Each of the quantities in Eq. 1 is highly uncertain: thus, their choice and probabilistic characterization is essential for the reliability of the results and the efficiency of the approach in practical application.

\subsection{The Site-Seismic Hazard}

In Eq. 1 the site seismic hazard is referred to a single parameter, usually an intensity measure IM, and is measured by the average frequency $\lambda$ (IM) with which each IM value is exceeded every year, while the seismic vulnerability of the construction is identified with the probability of overcoming each value of a structural damage parameter DM for any given IM. 
The ground motion intensity measure, IM, serves as an interface between the characterization of the seismic hazard and the assessment of the structural behavior.

In turn, the limit condition is described by an appropriate limit state, LS, corresponding to an appropriate performance requirement, whose achievement is probabilistically related to DM: the choice of the limit state and its relation with DM depend on several factors, such as the construction type, the structural model, the method of analysis.

As concerns the characterization of the seismic hazard, Eq. 1 is significant only insofar as:

(i) the seismic hazard, hence the damage potential of the earthquake, is consistently defined by the probabilistic characterization of the chosen IM;

(ii) in the relevant site, the frequency curve $\lambda$ (IM) can be evaluated by a probabilistic seismic hazard analysis;

(iii) the number of calculations that are needed to evaluate the structural response, taking into account the uncertainties of both the seismic motion and the structural properties, is not excessive.

These conditions are met if the parameter IM satisfies, respectively, the requirements of sufficiency, hazard valuableness and efficiency, as defined in [32] and discussed in [19], [13].

According to these definitions, an intensity measure IM is sufficient if DM for a given IM can be evaluated independently on any other property of the seismic motion, like magnitude of the generating event, source-to-site distance, fault type, soil type, and directivity effects. The adoption of a sufficient IM (i) permits an unbiased evaluation of $\lambda$ (LS) by Eq. 1. (ii) makes it not essential a careful selection of records to be used in non-linear dynamic analyses to take into account the record-to-record variability, (iii) legitimizes scaling the accelerograms [32], (iv) allows decoupling seismic hazard and structural analysis, and (iv) gives an exhaustive description (at least in a statistical sense) of the damaging power of the seismic event, thus overcoming the need of adopting a vector of parameters.

The hazard valuableness depends on the possibility of describing the source activity and the source-to-site attenuation law in terms of the chosen IM.

Finally, an IM is efficient if the uncertainties in the structural response, evaluated by considering a set of ground motion records scaled to different values of IM, are not excessive. This last condition can be quantified by limiting the value of the dispersion $\beta_{\mathrm{DMIIM}}$ of DM for each value of IM; since in Eq. 1 the structural response, thence the function $\mathrm{G}(\mathrm{DM} / \mathrm{IM})$ are evaluated by nonlinear dynamic analyses, the use of a more efficient IM implies a reduction in the number of analyses necessary to estimate $\lambda$ (LS) with the same confidence level.

From the definitions given above, it appears that sufficiency is an essential property of an IM. Once the sufficiency of a candidate IM is established, efficiency and hazard valuableness are two relative criteria that can be used to select a candidate IM among the alternative ones. However, the choice of IM depends strongly on the structural typology and the damage measure DM. 


\subsection{The Structural Vulnerability}

Also the choice of the proper DM, that completely characterize the structural response, should be carried out by checking both sufficiency and efficiency.

The DM sufficiency is related to the possibility of describing the damage state of the structure by the candidate DM, and of relating the seismic risk of the construction to the mean occurrence rate of overcoming each given value of DM. However, it may be really difficult to justify this choice, even only in a statistical sense.

The choice of DM is then related (i) to the relative efficiency of the candidate parameters, that can be measured (as for IM) by the dispersion $\beta_{\mathrm{DM} I \mathrm{IM}}$ of the values of DM resulting from nonlinear dynamic analyses for each value of IM, and (ii) to the possibility of estimating, in a consistent way, the type and parameters of the conditional distribution G(DMIIM).

In the present context, the structural response is evaluated by nonlinear incremental dynamic analysis (IDA). IDA [32] is a parametric nonlinear analysis that involves subjecting the structural model to a certain number of ground motion time histories, each of them scaled to multiple levels of intensity, that is, to a seismic action characterized by different occurrence rate, intensity and frequency content.

The use of IDA has many advantages: indeed, it describes the evolution of the structural response in the whole investigated range of seismic intensities and gives a visual description of the effects of the record-to-record variability.

The results of IDAs are given as plots of the structural response, that is, of the assumed damage measure, DM, as a function of the ground motion intensity measure, IM. Each IDA plot depends on the adopted DM and on the specific record, but not on the considered IM: IDA plots in terms of different IMs are easily obtained by scaling the ordinate of each point on the curve according to the relation between the originally adopted IM and the candidate IM.

\subsection{Seismic Risk Assessment}

Once the expressions of the relevant probability functions are defined, Eq. 1 can be evaluated by a numerical procedure.

However, if some simplifying assumptions hold, it is possible to attribute an analytic expression to $\lambda(\mathrm{LS})$, as described in detail in [19]. These assumptions are crucial and may introduce considerable epistemic uncertainties in the solution to Eq. 1, that cannot be quantified; therefore their contribution is disregarded in what follows.

As suggested by [23], let us assume that the site-seismic hazard $\lambda$ (IM) is described by a curve that is approximated, in the region of interest, by the power-law relationship:

$$
\lambda(\mathrm{IM})=P[\mathrm{IM} \geq x]=k_{0} \cdot(x)^{-k}
$$

where $k_{0}$ and $k$ are the parameters that define the shape of this hazard curve.

Observations of demand values are obtained from the results of incremental dynamic analyses, performed for various levels of IM. Considering any set of ground motion records applied to the structure, there will be a certain variability in the values of DM for each given level of IM. The record-to-record variability is a consequence of the 
variability of the generating events; however, also the uncertainties characterizing the structural parameters can be taken into account.

In order to build a simplified probabilistic model of the demand (the damage to the structure), DM can be written as:

$$
\mathrm{DM}=\eta_{\mathrm{DMIIM}} \cdot \varepsilon
$$

that is, as the product of the conditional median $\eta_{\text {DMIIM }}$ of DM given IM and a lognormal random variable $\varepsilon$; the median and the standard deviation of $\ln \varepsilon$ are set equal, respectively, to 1 and $\beta_{\mathrm{DM} I \mathrm{IM}}$, that in turn depends on the level of IM.

Let us introduce an approximate functional relationship between each IM value and the median $\eta_{\mathrm{DM} \text { IIM }}$ of the demand parameter DM, based on a regression of the results of time-history analyses. If the conditional median demand is approximated as a powerlaw function of IM, the relationship is given by:

$$
\eta_{\mathrm{DM} \mid \mathrm{IM}}=a \cdot \mathrm{IM}^{b}
$$

The conditional demand is thus the random variable:

$$
\mathrm{DM}=a \cdot \mathrm{IM}^{b} \cdot \varepsilon
$$

The standard deviation of the natural logarithm of DM given IM is equal to:

$$
\sigma_{\operatorname{lnDM} \mid \mathrm{IM}}(\mathrm{IM})=\beta_{\mathrm{DM} \mid \mathrm{IM}}
$$

According to this formulation, it is possible to obtain the demand hazard, that is, the mean annual frequency (i.e. the annual probability if some simplifying assumptions hold) of exceeding a certain level of DM, dm, for each given level of IM, im, by the relationship:

$$
\lambda(\mathrm{DM})=\int_{0}^{\infty} P[\mathrm{DM}>d m \mid \mathrm{IM}=i m] \cdot|d \lambda(\mathrm{IM})|=k_{0}\left(\frac{\mathrm{DM}}{a}\right)^{\frac{-k}{b}} \cdot e^{\frac{1}{2} \cdot \frac{k^{2}}{b^{2}} \cdot \beta_{\mathrm{DM} \mid \mathrm{IM}}^{2}}
$$

According to Eq.7 the demand hazard is given by the seismic hazard curve 2 evaluated at the IM value corresponding to the DM value times a factor related to the dispersion in demand for a given level of IM.

In order to derive the limit state annual frequency $\lambda(\mathrm{LS})$, that is a measure of the probability that the damage to the structure exceeds a threshold corresponding to the relevant limit state, which is an uncertain quantity representing the structural capacity $\mathrm{C}$, let us finally assume that the demand and the capacity are independent random variables and that the capacity is a lognormal random variable itself, with the following parameters: $\operatorname{median}(\mathrm{C})=\eta_{\mathrm{C}}, \sigma_{\ln (\mathrm{C})}=\beta_{\mathrm{C}}$. As:

$$
\lambda\left(\operatorname{IM}\left(\eta_{C}\right)\right)=k_{0}\left(\frac{\eta_{C}}{a}\right)^{\frac{-k}{b}}
$$

gives the value of the seismic hazard for the IM value corresponding to the median capacity $\eta_{\mathrm{C}}$, after some rearrangements [19], it is straightforward to obtain:

$$
\lambda(\mathrm{LS})=k_{0}\left(\frac{\eta_{C}}{a}\right)^{\frac{-k}{b}} \cdot e^{\frac{1}{2} \cdot \frac{k^{2}}{b^{2}} \cdot \beta_{\mathrm{DM} \mid \mathrm{IM}}^{2}} \cdot e^{\frac{1}{2} \cdot \frac{k^{2}}{b^{2}} \cdot \beta_{C}^{2}}
$$


In Eq.9 the limit state probability is expressed as the seismic hazard curve evaluated at the IM value corresponding to $\eta_{\mathrm{C}}$ (the median capacity) multiplied by two coefficients that take into account respectively the randomness in DM for a given IM (the demand factor) and the randomness in the capacity $\mathrm{C}$ itself (the capacity factor).

\section{An Application}

In this paper, the procedure summarized in Sect. 2 is applied to assess the seismic risk of the composite steel-concrete planar frame of Fig. 1] that is part of a spatial frame that has been subjected to pseudo-dynamic seismic tests [7].

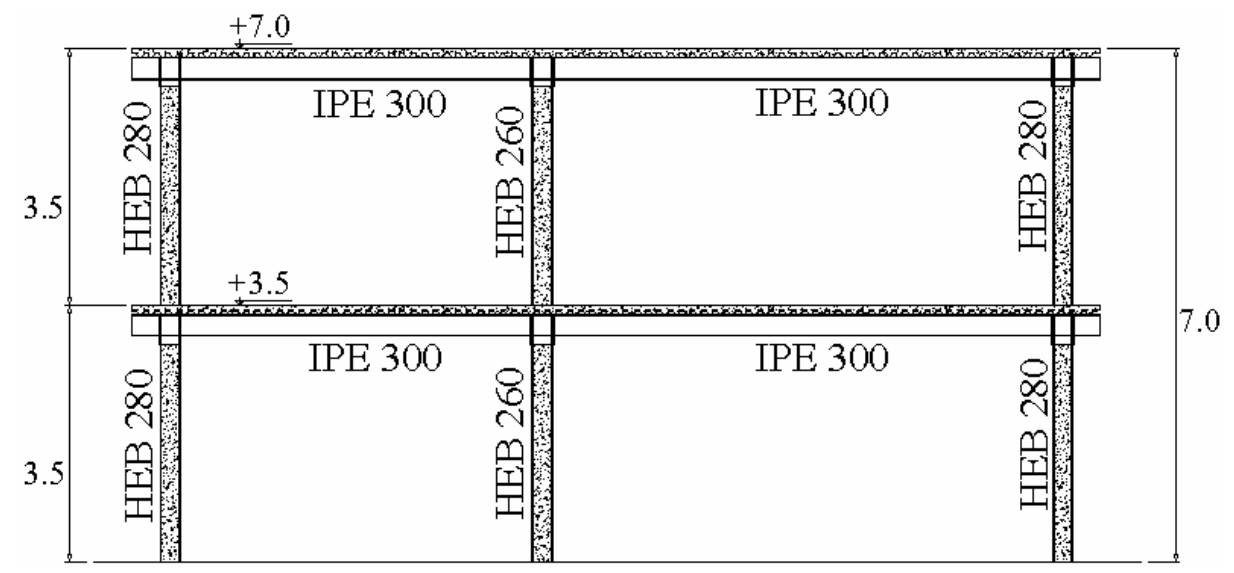

Fig. 1. Plane frame from a structure subject to pseudo-dynamic seismic tests at ELSA Laboratory, JRC, Ispra (Research project: ECOLEADER HPR-CT-1999-00059; ECSC 7210-PR-250) [7]

The structural model is shown in Fig. 2. The beam-column joints have been simulated as assemblages of translational and rotational nonlinear springs; their parameters have been calibrated by the results of experiments carried out on the whole spatial frame [5]. The moment-rotation relationships of the rotational springs for external and internal joints are plotted in Fig. 3 The nonlinear dynamic incremental analyses have been carried out by IDARC2D [18].

\subsection{Choice of IM}

As stated in Sect. 2.1, sufficiency and efficiency are the measures of the IM capability to eliminate the bias in formulating Eq. 1 and to reduce the variability of the structural response evaluated by IDA.

The most appropriate IM has been chosen by evaluating the sufficiency of various IMs, with reference also to other example cases of composite steel-concrete plane frames similar to the one represented in Fig. 1 and by choosing the most efficient IM among the sufficient ones. 


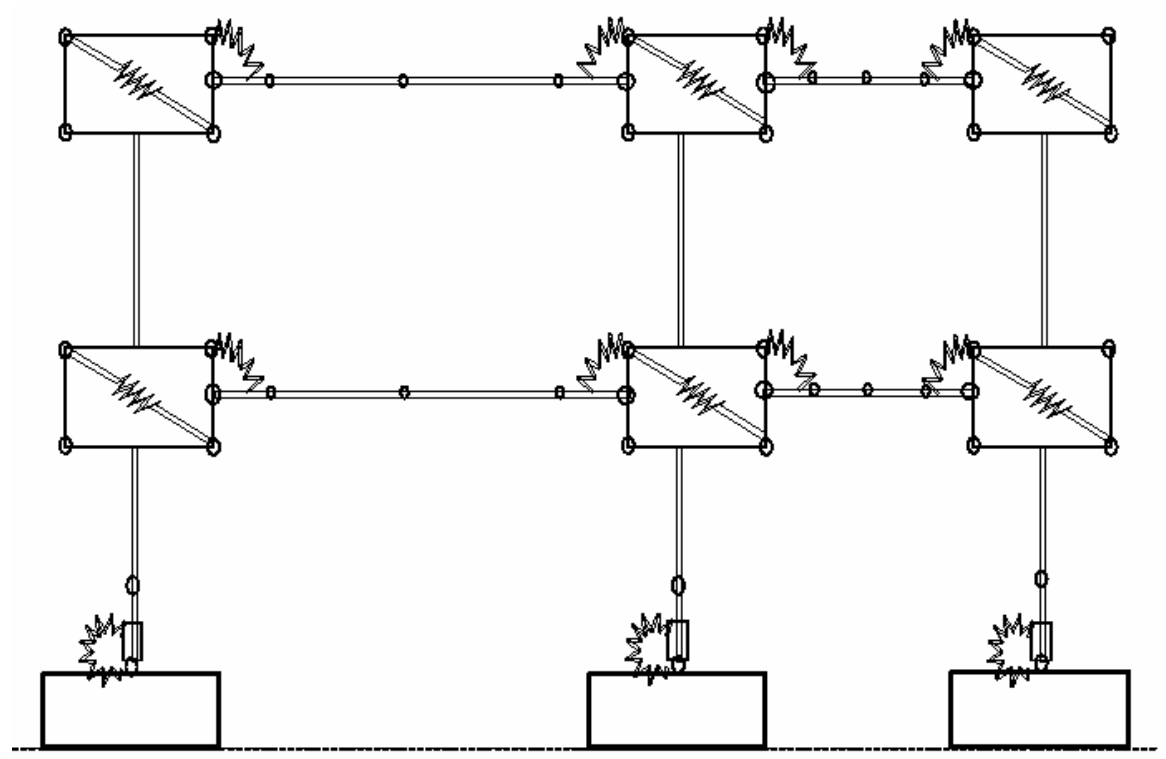

Fig. 2. Structural model of the frame with deformable joints [5]

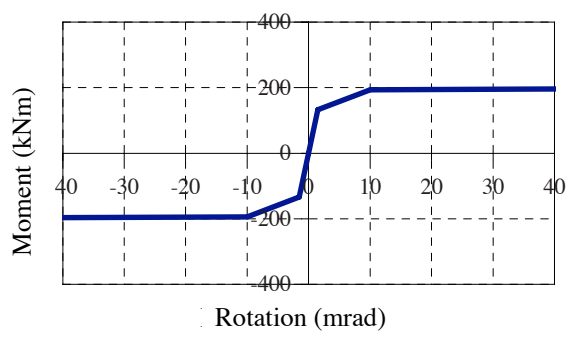

(a)

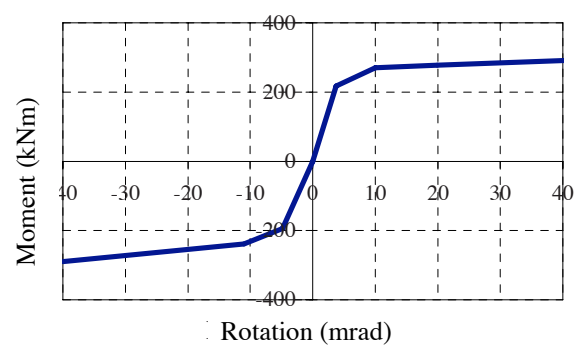

(b)

Fig. 3. Moment-rotation relationships for the external (a) and internal (b) joints derived from the experimental tests

The results illustrated in the following are specifically referred to the frame in Fig. 1, similar conclusions have been drawn by considering the other example cases [8].

After a series of preliminary analyses, presented in detail in [13], the selected candidate IMs were:

a) The peak ground acceleration, PGA.

b) The peak ground velocity, PGV.

c) The Housner Intensity, $I_{H}$, given by [16]:

$$
I_{H}=\int_{0.1}^{2.5} S_{V}(T, \xi) d T
$$


where: $S_{V}(\cdot)$ is the pseudo-spectral velocity; $T$ is the natural period; $\xi$ is the damping ratio.

d) The spectral intensity, $\mathrm{Sa}\left(T_{1}\right)$, that is, the $\xi$ damped spectral pseudo-acceleration at the fundamental period $T_{1}$ of the structure.

e) The two-parameter scalar IM proposed by [10], $\mathrm{SaC}$, and defined as:

$$
\mathrm{SaC}=\mathrm{Sa}\left(T_{1}\right)\left(\frac{\mathrm{Sa}\left(c \cdot T_{1}\right)}{\mathrm{Sa}\left(T_{1}\right)}\right)^{\alpha}
$$

where: $\mathrm{Sa}(\cdot)$ is the ordinate of the pseudo-acceleration response spectrum; $c$ and $\alpha$ are parameters that are usually derived from an ad-hoc calibration. In numerical calculations, $\alpha$ has been taken equal to 0.5 ; $c$ has been taken equal either to 2 , as suggested in [10], to take into account the effect of period lengthening due to nonlinear behavior, or to $T_{2} / T_{1}$ (where $T_{2}$ is the period of the second mode of vibration of the considered structure). Both alternatives for $c$ have been considered because the latter, as suggested in [13], led to a more efficient IM in case of slender structures whose behavior is influenced by higher modes of vibration.

f) The spectral pseudo-acceleration averaged over a period interval [20], defined as:

$$
\mathrm{Sa}_{a v}=\frac{1}{b^{\prime}-a^{\prime}} \int_{a^{\prime}}^{b^{\prime}} \mathrm{Sa}(T) d T .
$$

As suggested in [20], in numerical calculations the following alternative pairs have been introduced: $a^{\prime}=T_{1}, b^{\prime}=1.5 T_{1}$, and: $a^{\prime}=T_{2}, b^{\prime}=T_{1}$.

As one of the objectives of this study is the selection of appropriate IM and DM for composite steel-concrete frames, the structural response has been evaluated by using as input 30 accelerograms obtained from the PEER data base [http://peer.berkeley.edu/smcat], but not selected on the basis of the Probabilistic Seismic Hazard Analysis of any specific site; the accelerograms have been scaled to different intensity levels, until the collapse of the frame was reached, it being identified by the lack of convergence of the numerical solution (that is, by global dynamic instability). Records with potential near-source effects, like directivity, have been discarded; no other specific criteria have been adopted in selecting the records.

The selected records had moment magnitude $\mathrm{M}$ between 5.5 and 7.0 and source-tosite distance R between $13 \mathrm{~km}$ and $60 \mathrm{~km}$.

The sufficiency of each candidate IM has been evaluated by a slightly refined version of the procedure based on the analysis of a set of linear regressions together with tests of hypothesis, proposed in [28], [19].

The significant ground motion characteristics are those included in the assumed attenuation law (in the example case, the law by [1]), namely, the moment magnitude $\mathrm{M}$, the source-to-site distance $\mathrm{R}$, and the error term $\varepsilon$ describing the model uncertainty.

As the sufficiency of IM depends on the structural typology and the damage measure, four different DMs have been considered:

I. The maximum interstory drift ratio, MIDR.

II. The global interstory drift ratio or roof drift angle, RDA.

III. The peak floor (absolute) acceleration, PFA.

IV. The peak floor (relative) velocity, PFV. 
MIDR is commonly adopted to describe the level of seismic damage, as it is relatively easy to establish a correlation between its values and the level of damage to both structural and non structural components. RDA is a global indicator, strictly related to the first one. PFA and PFV can be considered as consistent indicators of the structural response and of the damage to the building content [9].

To evaluate the sufficiency of the candidate IMs, residual-residual plots have been obtained for each IM, considering the alternative DMs. These plots indicate the significance of each additional regression variable ( $\mathrm{M}, \mathrm{R}$ and $\varepsilon$ ) by indicating whether a second variable introduced in the model of the site-seismic hazard significantly improves the prediction of the structural response.

The plots, illustrated in detail in [8] are constructed by performing a regression of the dependent variable (the selected DM) versus the first independent variable (the candidate IM); then by performing the regressions of each secondary independent variable $(\mathrm{M}, \mathrm{R}$ or $\varepsilon$ ) on the first variable; finally, by plotting the residuals of the primary regression against the residuals of each secondary regression.

By observing in these residual-residual plots a statistically significant trend between the two sets of residuals, the potential dependence of the dependent variable on the secondary variable can be investigated.

The trend is quantified by the slope $b^{*}$ of the regression line in each residual-residual plot; if $b^{*}$ is "different" from 0 , the residuals of the primary regression are correlated to the residuals of the secondary regression, and the candidate IM is not sufficient with respect to the considered secondary variable. A test of hypothesis based on the Student$\mathrm{t}$ distribution has been applied to verify if the null hypothesis $\left(b^{*}=0\right)$ can be rejected; this happens if the $p^{-}$value is smaller than 0.05 .

As a case example, consider MIDR as the damage measure. The results of the tests of hypothesis referred to $\mathrm{M}$ and $\mathrm{lnR}$ are reported in Tables 1 and 2 , comparable results have been obtained for the other DMs [8].

The $\mathrm{a}^{*}$ values reported in Tables 1 and 2 are the intercepts of the regression lines in the residual-residual plots. These values are very small (they should be equal to 0), as the regression prediction always passes through the average values of the two sets of horizontal and vertical components, and these average values must be equal to 0 as the two sets of components are themselves residuals of linear regression.

Table 1. Check of sufficiency with respect to $\mathrm{M}$

\begin{tabular}{|l|l|l|l|l|l|l|l|}
\hline Magnitude & $\sigma_{0}$ & $\sigma$ & $\mathbf{a}^{*}$ & $\mathbf{b}^{*}$ & $\sigma_{b}$ & $\mathbf{p}$-value & $\begin{array}{l}\text { Check of } \\
\text { sufficiency }\end{array}$ \\
\hline PGA & 0.4367 & 0.3138 & $-1.33 \mathrm{E}-15$ & 0.2124 & 0.1189 & 0.04250 & No \\
\hline PGV & 0.4312 & 0.4146 & $-2.25 \mathrm{E}-15$ & -0.2228 & 0.1470 & 0.0704 & Yes \\
\hline$I_{H}$ & 0.4372 & 0.4285 & $1.82 \mathrm{E}-15$ & -0.1581 & 0.1474 & 0.1464 & Yes \\
\hline $\mathbf{S a}\left(\mathbf{T}_{\mathbf{1}}\right)$ & 0.2511 & 0.2309 & $-3.02 \mathrm{E}-15$ & 0.1511 & 0.0667 & 0.0157 & No \\
\hline $\mathbf{S a C}(\mathbf{c}=\mathbf{2}, \alpha=\mathbf{0 . 5})$ & 0.3162 & 0.3161 & $-2.31 \mathrm{E}-15$ & -0.0160 & 0.0980 & 0.4358 & Yes \\
\hline $\mathbf{S a C}\left(\mathbf{c}=\mathbf{T}_{\mathbf{2}} / \mathbf{T}_{\mathbf{1}}, \alpha=\mathbf{0 . 5}\right)$ & 0.3793 & 0.3505 & $-3.60 \mathrm{E}-16$ & 0.2191 & 0.2000 & 0.0685 & Yes \\
\hline Saav $\left(\mathbf{T}_{\mathbf{1}} \div \mathbf{1 . 5 \mathbf { T } _ { 1 } )}\right.$ & 0.2702 & 0.2662 & $-5.98 \mathrm{E}-16$ & 0.0725 & 0.0792 & 0.1838 & Yes \\
\hline Saav $\left(\mathbf{T}_{\mathbf{2}} \div \mathbf{1 . 5 \mathbf { T } _ { \mathbf { 1 } } )}\right.$ & 0.2519 & 0.2503 & $-8.39 \mathrm{E}-16$ & 0.0462 & 0.0751 & 0.2715 & Yes \\
\hline
\end{tabular}


Table 2. Check of sufficiency with respect to $\ln \mathrm{R}$

\begin{tabular}{|l|l|l|l|l|l|l|l|}
\hline Source-to-site distance $\boldsymbol{R}$ & $\sigma_{0}$ & $\sigma$ & $\mathbf{a}^{*}$ & $\mathbf{b}^{*}$ & $\sigma_{b}$ & $\mathbf{p}$-value & $\begin{array}{l}\text { Check of } \\
\text { sufficiency }\end{array}$ \\
\hline PGA & 0.4367 & 0.4190 & $-1.01 \mathrm{E}-15$ & 0.2661 & 0.1713 & 0.06582 & Yes \\
\hline $\mathbf{P G V}$ & 0.4312 & 0.4306 & $-1.86 \mathrm{E}-15$ & -0.0522 & 0.1781 & 0.3858 & Yes \\
\hline$I_{H}$ & 0.4372 & 0.4367 & $1.77 \mathrm{E}-15$ & -0.0473 & 0.1805 & 0.3977 & Yes \\
\hline $\mathbf{S a}\left(\mathbf{T}_{\mathbf{1}}\right)$ & 0.2511 & 0.2268 & $-2.83 \mathrm{E}-15$ & 0.2328 & 0.0926 & 0.0090 & No \\
\hline $\mathbf{S a C}(\mathbf{c}=\mathbf{2}, \alpha=\mathbf{0 . 5})$ & 0.3162 & 0.3090 & $-2.58 \mathrm{E}-15$ & 0.1458 & 0.1261 & 0.1288 & Yes \\
\hline $\mathbf{S a C}\left(\mathbf{c}=\mathbf{T}_{\mathbf{2}} / \mathbf{T}_{\mathbf{1}}, \alpha=\mathbf{0 . 5}\right)$ & 0.3793 & 0.3508 & $-1.70 \mathrm{E}-16$ & 0.3131 & 0.2437 & 0.1900 & Yes \\
\hline $\mathbf{S a a v}\left(\mathbf{T}_{\mathbf{1}} \div \mathbf{1 . 5 T _ { 1 } )}\right.$ & 0.2702 & 0.2608 & $-6.38 \mathrm{E}-16$ & 0.1522 & 0.1065 & 0.0820 & Yes \\
\hline $\mathbf{S a a v}\left(\mathbf{T}_{\mathbf{2}} \div \mathbf{1 . 5} \mathbf{T} \mathbf{1}\right)$ & 0.2519 & 0.2467 & $-7.89 \mathrm{E}-16$ & 0.1107 & 0.1008 & 0.1407 & Yes \\
\hline
\end{tabular}

To refine the statistical estimate, the test of hypothesis has been repeated by characterizing the regression in the residual-residual plot by the Pearson's or Spearman's coefficients, and by adopting the procedure of non parametric regression proposed by [31]. The obtained results have confirmed those reported in Tables 1 and 2] as illustrated in [8].

In Tables 1 and 2, also the square root of the mean of squares (rms) $\sigma_{0}$ of the primary regression of the dependent variable (the considered DM) on the first variable (the candidate IM) and the rms $\sigma$ of the residual-residual regression are reported. These two quantities can be used to measure the significance of each additional variable in reducing the variability of data, as the smaller the ratio of these two quantities, the more significant is the role of the secondary variable.

Moreover, if the standard deviation $\sigma_{b}$ (also shown in Tables 1 and 2 ) is very large relative to the slope $b^{*}$ itself, the slope may not be statistically different from zero.

It can be concluded that PGA is not sufficient with respect to $\mathrm{M}$ : indeed, $\sigma_{0}$ is quite different from $\sigma$, and the p-value is significantly lower than 0.05 . The same result applies to $\mathrm{Sa}\left(T_{1}\right)$ if both $\mathrm{M}$ and $\mathrm{R}$ are considered.

In order to evaluate the efficiency of the three left IMs, that satisfy sufficiency, their values corresponding to each level of DM have been calculated, and the cross-sectional counted percentiles (e.g., $\mathrm{im}^{16 \%}, \mathrm{im}^{50 \%}, \mathrm{im}^{84 \%}$ ) estimated. If the distribution of IM given DM is assumed to be lognormal, the estimator of the dispersion of the values of IM is given by [19]:

$$
\beta_{\mathrm{IM} \mid \mathrm{DM}}(\mathrm{dm})=\frac{1}{2} \ln \left[\frac{\mathrm{im}^{84 \%}}{\mathrm{im}^{16 \%}}\right]
$$

The value of $\beta_{\mathrm{IMIDM}}(\mathrm{dm})$ has thus been assumed as the measure of the efficiency of each candidate IM for the considered value of DM: indeed, the number of nonlinear dynamic analyses to be run in order to evaluate $\lambda(\mathrm{LS})$ in Eq. 1 with a given confidence level, increase if $\beta_{\mathrm{IMIDM}}(\mathrm{dm})$ is higher.

It should also be noted that each limit state condition is usually associated to a threshold value of DM: the values of $\beta_{\mathrm{IMIDM}}(\mathrm{dm})$ could also be used as the estimators of the dispersion of the structural capacity at the corresponding successive damage states [13].

In Table 3 , the lowest values of $\beta_{\mathrm{IMIDM}}$ are evidenced by italic, for some discrete values of the considered DMs, representative of low, moderate or significant damage 
Table 3. Dispersion of the results for two different values of the various DMs and the sufficient IMs

\begin{tabular}{|c|c|c|c|c|c|c|c|c|}
\hline DM & \multicolumn{2}{|c|}{ MIDR } & RDA & & PFA & {$[\mathrm{m} / \mathbf{s} 2]$} & PFV & {$[\mathrm{m} / \mathrm{s}]$} \\
\hline \begin{tabular}{|l|} 
IM \\
\end{tabular} & 0.01 & 0.05 & 0.005 & 0.02 & 3.00 & 9.00 & 0.40 & 1.10 \\
\hline PGV & 0.399 & 0.451 & \begin{tabular}{|l|}
0.393 \\
\end{tabular} & 0.462 & 0.406 & 0.447 & 0.333 & 0.476 \\
\hline $\bar{I} I_{H}$ & 0.269 & 0.382 & 0.256 & 0.389 & 0.366 & 0.407 & 0.277 & 0.409 \\
\hline $\mathrm{SaC}(\mathbf{c}=2 ; \alpha=0.5)$ & 0.100 & 0.347 & 0.142 & 0.349 & 0.371 & 0.458 & 0.233 & 0.366 \\
\hline $\mathbf{S a C}\left(c=\mathbf{T}_{2} / \mathbf{T}_{1} ; \alpha=0.5\right)$ & 0.251 & 0.446 & 0.267 & 0.436 & 0.240 & 0.386 & 0.257 & 0.455 \\
\hline $\mathbf{S a C}\left(\mathbf{c}=\mathbf{T}_{2} / \mathbf{T}_{1}, \alpha=0.5\right)$ & 0.364 & 0.465 & 0.379 & 0.468 & 0.252 & 0.445 & 0.275 & 0.473 \\
\hline $\operatorname{Saav}\left(T_{1} \div 1.5 T_{1}\right)$ & 0.269 & 0.301 & 0.379 & 0.305 & 0.393 & 0.304 & 0.228 & 0.300 \\
\hline $\operatorname{Saav}\left(T_{2} \div 1.5 T_{1}\right)$ & 0.224 & 0.282 & 0.304 & 0.312 & 0.417 & 0.305 & 0.136 & 0.313 \\
\hline
\end{tabular}

states. As demonstrated in [13] with reference to reinforced concrete frames, $\mathrm{SaC}$ (with parameters: $\mathrm{c}=2 ; \alpha=0.5$ ) gives acceptable results also when the damage is limited.

In the end, $\mathrm{SaC}$ has been chosen as the "best" intensity parameter, because: it is sufficient; it is efficient; it is easy to derive the hazard in the relevant site in terms of $\mathrm{SaC}$, as it is a weighted average of two values of the spectral intensity $\mathrm{Sa}(T)$ and the attenuation laws in terms of $\mathrm{Sa}(T)$ are well known and reliable.

\subsection{Choice of DM}

In order to define the damage to the structure, various DMs have been compared in terms of their efficiency. [34] provide a detailed summary of the available DMs.

In addition to those considered in evaluating the efficiency of the candidate IMs (cf. Sect. 3.1), specific attention has been given to four indices representing a measure of the local damage to the structure. They are all able to take into account the nonlinear response and the dissipation of energy due to plastic deformations. Their choice is thus justified by the model adopted for evaluating the structural response, and specifically for the beam-column joints, that, as demonstrated by the experiments, are the most vulnerable components of the structural system. The additional candidate DMs were:

V. The ratio $\mu$ between the maximum required and the available curvature ductility in a set of control points.

VI. The maximum normalized dissipated energy, E, in the joints.

VII. The Park-Ang index, P\&A, evaluated as a linear combination of the maximum ductility response and the total hysteretic energy dissipation [25] as:

$$
P \& A=\frac{\mu_{\mathrm{max}}}{\mu_{\mathrm{mon}}}+\beta \frac{E_{H}}{M_{y} \cdot \theta_{\mathrm{mon}}}
$$

where: $\mu_{\max }$ and $\mu_{\operatorname{mon}}$ represent the maximum ductility response for a given earthquake history and the available ductility in the corresponding plastic zone; $\beta$ is an empirical factor, that came out equal to 0.30 according to the calibration described below; $E_{H}$ is the total hysteretic energy dissipated in the plastic zone for the given earthquake history; $M_{y}$ is the yielding moment; $\theta_{\text {mon }}$ is the maximum admissible rotation. This damage measure, while referring to a local behavior, gives some 
information about the seismic damage, as it takes into account both the maximum required ductility and the dissipated energy, that is, the maximum value of the structural response and the degradation of strength and stiffness due to cyclic behavior. The factor $\beta$ in Eq. 14 has been calibrated by submitting several examples of composite steel-concrete frames to IDA, and putting P\&A = 1 when the collapse of each examined structure occurred in each nonlinear dynamic analysis. The final value $\beta=0.30$ has been the average value of all obtained results.

VIII. The Banon-Veneziano index, B\&V [3], given by:

$$
B \& V=\sqrt{\left(D_{1}^{*}\right)^{2}+\left(D_{2}^{*}\right)^{2}}
$$

where, indicating by $x_{\max }$ and $x_{y}$ the maximum and the yield displacements respectively, and by $F_{y}$ the yielding strength in the corresponding plastic zone,

$$
\begin{gathered}
D_{1}^{*}=D_{1}-1=\mu_{s}-1 ; \quad D_{2}^{*}=a^{\prime} \cdot D_{2}^{b^{\prime}}=a^{\prime}\left[2\left(\mu_{e}-1\right)\right]^{b^{\prime}} \\
D_{1}=\frac{x_{\max }}{x_{y}}=\mu_{s} ; \quad D_{2}=\frac{E_{H}}{0.5 F_{y} x_{y}}
\end{gathered}
$$

The parameters $a^{\prime}$ and $b^{\prime}$ have been set: $a^{\prime}=1.1 ; b^{\prime}=0.38$, as suggested by Banon and Veneziano themselves.

The efficiency of all DMs has been quantified by the dispersion $\beta_{\mathrm{DMIIM}}$ of the IDA plots, evaluated by Eq. 13, It has been found that, due to the assumed structural model, the most significant DMs are the latter four [8].

Table 4. Mean value of $\beta_{\mathrm{DM}}$ IIM obtained by assuming $\mathrm{SaC}$ as IM and averaging on three values of the corresponding DM

\begin{tabular}{|l|l|l|l|l|l|}
\hline$\beta_{\mathrm{DM} \mid \mathrm{IM}}$ & $\mathrm{MIDR}$ & $\mathrm{P} \& \mathrm{~A}$ & $\mathrm{~B} \& \mathrm{~V}$ & $\mu$ & $\mathrm{E}$ \\
\hline $\mathrm{SaC}$ & 0.64 & 0.51 & 0.57 & 0.60 & 0.55 \\
\hline
\end{tabular}

The values of $\beta_{\mathrm{DMIIM}}$ for these four DMs and three values of $\mathrm{SaC}$ are compared in Fig. 4 In Table 4 the values of $\beta_{\text {DMIIM }}$ averaged over three different levels of damage (light, moderate, severe) are shown. They have been evaluated by considering the IDA plots reported in Fig. 5]

\subsection{Site-Seismic Hazard}

The seismic hazard curve of Fig. 6has been elaborated from data available for Reggio Calabria (South Italy) in the Seismic Catalogue elaborated by the Italian National Group for Seismic Risk Reduction [22]; the parameters $k_{0}$ and $k$ in Eq. 22 have been obtained by a regression in the logarithmic plane. 


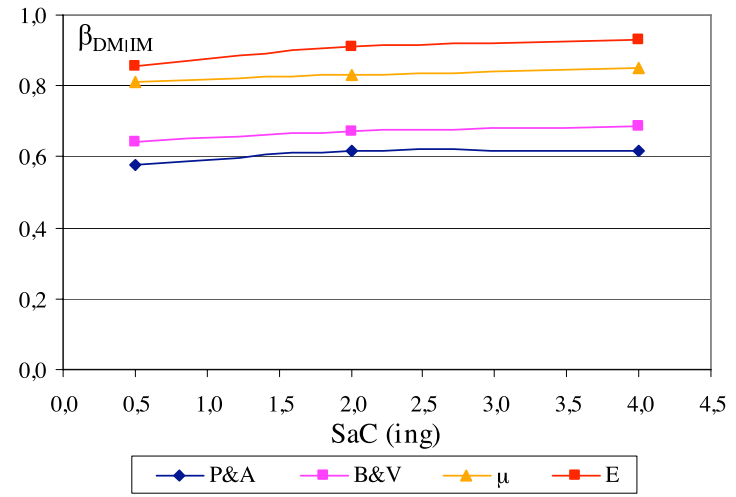

Fig. 4. Values of $\beta_{\mathrm{DM} I \mathrm{IM}}$ evaluated for the four local DMs in correspondence to three values of $\mathrm{SaC}$
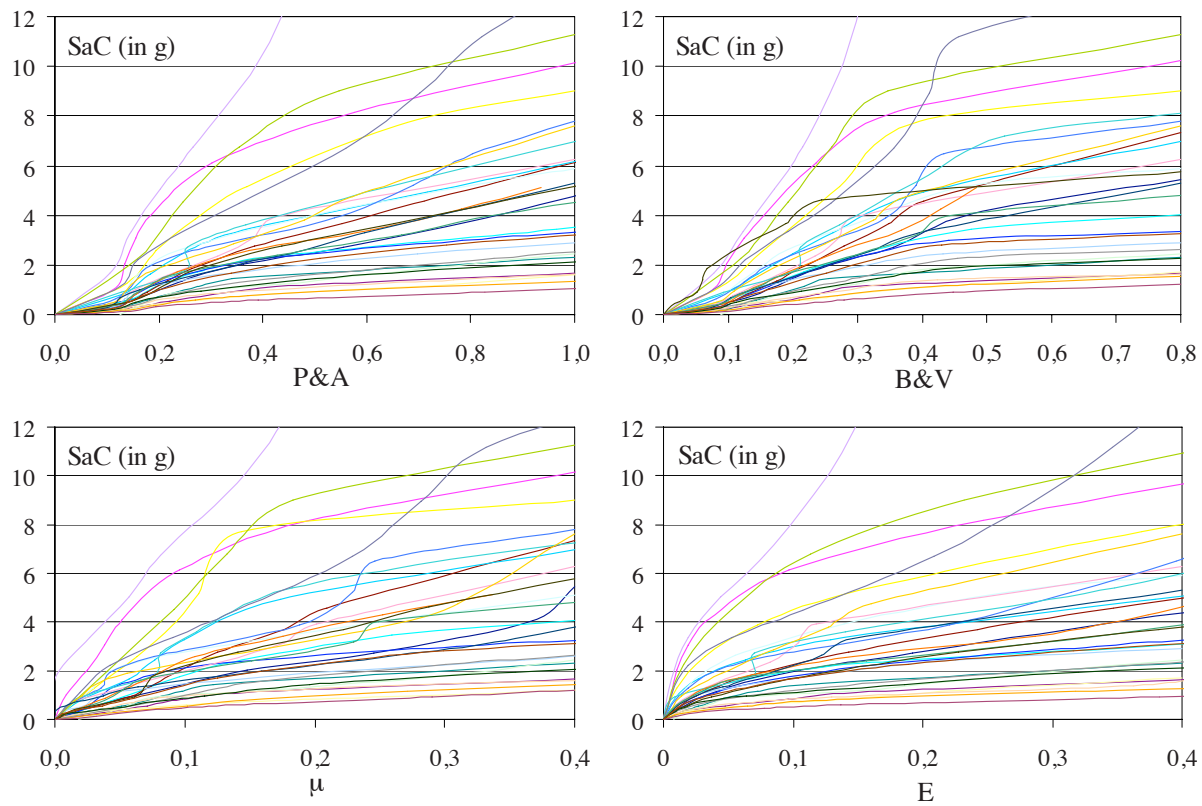

Fig. 5. IDA plots: the four local damage indices are assumed as $\mathrm{DM} ; \mathrm{SaC}$ is assumed as IM

\subsection{Seismic Risk Assessment}

The median values of P\&A derived by IDAs are plotted in Fig. 7 as a function of SaC; the parameters $a$ and $b$ in Eq. 4 are obtained by the plotted regression, while the values of $\beta_{\text {DMIIM }}$ in Eq.7 7have been obtained by the plots in Fig. 5. 


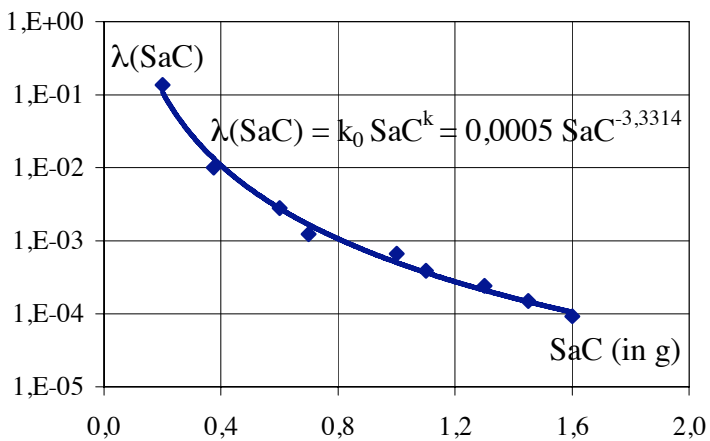

Fig. 6. Assumed seismic hazard curve

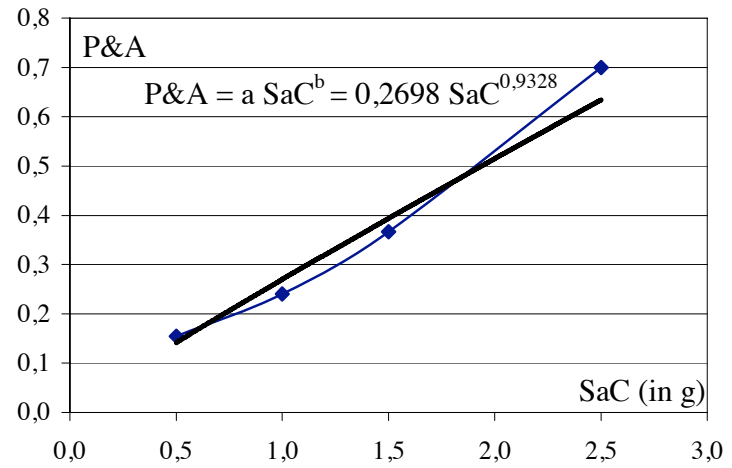

Fig. 7. Median values of $\mathrm{P} \& \mathrm{~A}$ as a function of $\mathrm{SaC}$

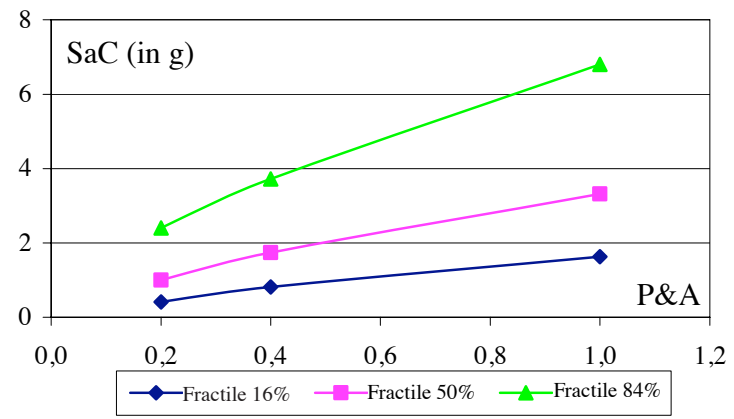

Fig. 8. Median and fractile values of $\beta \mathrm{IM} / \mathrm{DM}(\mathrm{IM}=\mathrm{SaC} ; \mathrm{DM}=\mathrm{P} \& \mathrm{~A})$

In Fig. 8 the $50 \%, 16 \%$ and $84 \%$ percentiles of $\beta_{\text {IMIDM }}$ are reported for three values of P\&A; by considering the median values, the median value $\eta_{\mathrm{C}}$ of the system capacity (Eq. 9) has been obtained. 


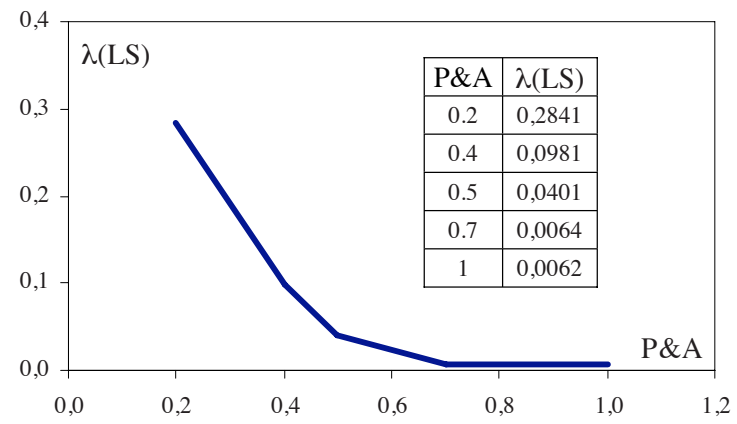

Fig. 9. Seismic risk of the frame: mean yearly frequency of exceeding the corresponding value of Park \& Ang index in a significant structural element (beam, column or joint)

The dispersion $\beta_{\mathrm{C}}$ of the system capacity (Eq. 9) has been evaluated by considering all points of the IDA plots in which a significant change of the slope occurs. By a regression of these values (linear in the logarithmic plane), it has been found that $\beta_{\mathrm{C}}=$ 0.395 .

In this paper, the median value and the dispersion of each element capacity have been determined from the results of IDA. Actually however, the capacity depends on the dimensions of the element and the material properties: therefore the median value and the dispersion of the capacity should be determined by experiments or field observations.

Finally, Fig. 9 shows the mean annual exceedance frequency $\lambda(\mathrm{LS})$ of the largest P\&A index in a significant structural element (beam, column, or beam-column joint).

The curve in Fig. 9 quantifies the seismic risk of the frame: in fact, it allows to evaluate the seismic performance of the system considering appropriate threshold values of P\&A, e.g. those reported in Table 4, and checking if the correspondent exceeding probability is admissible.

Table 5. Range of P\&A values corresponding to different damage states of the structure

\begin{tabular}{|l|l|l|}
\hline Damage level & P\&A & State of the structure \\
\hline Collapse & $\geq 1$ & Collapsed \\
\hline Severe & $0.5 \div 0.9$ & Heavily damaged \\
\hline Moderate & $0.2 \div 0.5$ & Operational \\
\hline Light & $0.0 \div 0.2$ & Fully operational \\
\hline
\end{tabular}

\section{Conclusions}

As noted in the Introduction, PBD should cover all stages of the facility design, but at present is still more a philosophy than a consistent framework, and has been mostly developed for seismic design of structures. This is also the limitation of this paper, that intends only to show critically the application of PBD to a concrete example. In particular the need has been underlined of a careful selection of the parameters that characterize the seismic hazard and the structural response. 
Acknowledgements. The numerical results presented in this paper were obtained in the framework of a "Research Project of National Interest" (PRIN) financially supported by the (Italian) Ministry for Education, University and Research MIUR (2003/2005). A preliminary version of this paper was presented orally at the "Henderson Colloquium" of the IABSE British Group (Cambridge, July 2005).

\section{References}

1. Abrahamson, N.A., Silva, W.J.: Empirical response spectral attenuation relations for shallow crustal earthquakes. Seismological Research Letters 68(1), 94-127 (1997)

2. Applied Technology Council (ATC): NEHRP guidelines for seismic rehabilitation of buildings: Report No. FEMA - 273, Federal Emergency Management Agency, WA, D.C. (1997)

3. Banon, H., Veneziano, D.: Seismic safety of reinforced concrete members and structures. Earthquake Engineering and Structural Dynamics 10, 179-193 (1982)

4. Bartoli, G., Ricciardelli, F., Saetta, A., Sepe, V. (eds.): Performance of Wind-Exposed Structures: Results of the PERBACCO Project. Firenze University Press (2006)

5. Braconi, A., Bursi, O., Ferrario, F., Salvatore, W.: Seismic design of beam-to-column connections for steel-concrete composite moment resisting frames. In: Fourth International Conference STESSA 2003: Behaviour of Steel Structures in Seismic Areas, Napoli, Italy (2003)

6. Burns, S., Bostrom, A.: Barriers to implementation of performance based engineering: lessons from the Tennessee 2003 international building code hearings. In: 2004 ANCER Annual Meeting: Networking of Young Earthquake Engineering Researchers and Professionals, Honolulu, Hawaii (2004)

7. Bursi, O.S., Molina, J., Salvatore, W., Taucer, F.: Dynamic characterization of a 3-d full scale steel-concrete composite building at elsa. Technical report, European Commission, Joint Research Centre, ELSA, EUR 21206 EN (2004)

8. Ciampoli, M.: Performance reliability of earthquake-resistant steel-concrete composite structures. In: Scientific research programmes of relevant national interest (2003),

http://www2.ing.unipi.it/dis/sismoresistenti/national.html (in Italian)

9. Ciampoli, M., Augusti, G.: Vulnerabilità sismica degli oggetti esibiti nei musei: interventi per la sua riduzione. In: Vulnerabilità dei beni archeologici e degli oggetti esibiti nei musei, pp. 85-104. CNR-Gruppo Nazionale per la Difesa dai Terremoti (2000)

10. Cordova, P.P., Deierlein, G.G., Mehanny, S.S.F., Cornell, C.A.: Development of a twoparameter seismic intensity measure and probabilistic assessment procedure. In: 2nd U.S.Japan Workshop on Performance-Based Earthquake Engineering for Reinforced Concrete Building Structures, Sapporo, Japan (2000)

11. Cornell, C.A., Krawinkler, H.: Progress and challenges in seismic performance assessment (2000),

http: / /peer.berkeley.edu/news /2000spring/performance/html. febwetg 4 wt 4

12. European Committee for Standardization (CEN): EN 1990: Eurocode - Basis for Structural Design, Technical Report, Brussels, Belgium (2002)

13. Giovenale, P., Ciampoli, M., Jalayer, F.: Comparison of ground motion intensity measure using the incremental dynamic analysis. In: ICASP'9, San Francisco, USA, pp. 1483-1491. Millpress, Rotterdam (2003)

14. Hadjian, A.H.: A general framework for risk-consistent seismic design. Earthquake Engineering and Structural Dynamics 31, 601-626 (2002) 
15. Hamburger, R.O., Moehle, J.P.: State of performance based-engineering in the United States. In: Second US-Japan Workshop on Performance-Based Design Methodology for Reinforced Concrete Building Structures, Sapporo, Japan (2000)

16. Housner, G.: Spectrum intensities of strong motion earthquakes. In: Symposium on Earthquake and Blast Effect on Structures, Los Angeles, California, pp. 20-36 (1952)

17. ICC: International performance code for buildings and facilities. Technical report, International Code Council, Falls Curch, VA (2001)

18. IDARC2D: A computer program for seismic inelastic structural analysis - version 5.5. University at Buffalo, Department of Civil, Structural and Environmental Engineering (1987)

19. Jalayer, F.: Direct probabilistic seismic analysis. Implementing non-linear dynamic assessments. PhD thesis, Stanford University (2003)

20. Kennedy, R.P., Short, S.A., Merz, K.L., Tokarz, F.J., Idriss, I.M., Power, M.S., Sadigh, K.: Engineering characterization of ground motion - task I: Effects of characteristic of free field motion on structural response. Technical report, NUREG/CR-3805, U.S. NRC, Washington D.C (1984)

21. Krawinkler, H.: Challenges and progress in performance-based earthquake engineering. In: International Seminar on Seismic Engineering for Tomorrow, Tokyo, Japan (1999)

22. Lucantoni, A., Bosi, V., Bramerini, F., De Marco, R., Lo Presti, T., Naso, G., Sabetta, F.: Il rischio sismico in Italia. Ingegneria Sismica 1, 5-36 (2001)

23. Luco, N., Cornell, C.A.: Structure-specific scalar intensity measures for near-source and ordinary earthquake ground motions. Earthquake Spectra 23(2), 357-392 (2007)

24. Ministero delle Infrastrutture e dei Trasporti: Norme tecniche per le costruzioni, Technical Report, Decreto 14 Settembre 2005, Roma (2005)

25. Park, Y.J., Ang, A.-H.S.: Mechanistic seismic damage model for reinforced concrete. Journal of Structural Engineering 111, 722-739 (1985)

26. SAC Joint Venture: Recommended post-earthquake evaluation and repair criteria for welded steel moment-frame buildings. Technical Report FEMA - 352, Federal Emergency Management Agency, WA, D.C. (2000)

27. SAC Joint Venture: Recommended seismic design criteria for new steel moment-frame buildings. Technical Report FEMA - 350, 350, Federal Emergency Management Agency, WA, D.C. (2000)

28. SAC Joint Venture: Recommended seismic evaluation and upgrade criteria for existing welded steel moment-frame buildings. Technical Report FEMA - 351, Federal Emergency Management Agency, WA, D.C. (2000)

29. SEAOC: Vision 2000 - a framework for performance based design (I-III). Technical report, Structural Engineers Association of California, Sacramento, CA (1995)

30. Sibilio, E., Ciampoli, M.: Performance-based wind design for footbridges: evaluation of pedestrian comfort. In: Proceedings, ICASP10, Japan (2007) (in press)

31. Theil, H.: Economics and Information Theory. Rand McNally and Company, Chicago (1967)

32. Vamvatsikos, D., Cornell, C.A.: Incremental dynamic analysis. Earthquake Engineering and Structural Dynamics 31(3), 491-514 (2002)

33. Whittaker, A.S., Hamburger, R.O., Mahoney, M.: Performance-based engineering of buildings and infrastructure for extreme loadings. In: Proceedings, AISC-SINY Symposium on Resisting Blast and Progressive Collapse. American Institute of Steel Construction, New York (2003)

34. Williams, M.S., Sexsmith, R.G.: Seismic damage indices for concrete structures: a state-ofthe-art review. Earthquake Spectra 11(2), 319-349 (1995) 